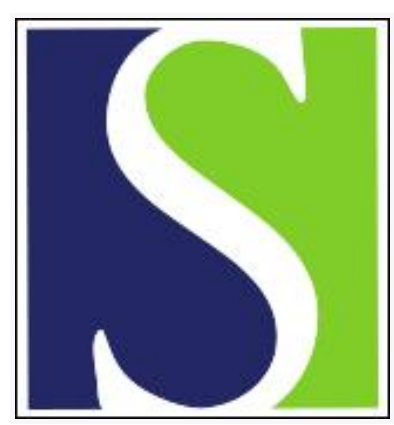

Scand J Work Environ Health 1991;17(6):420-424

https://doi.org/10.5271/sjweh.1680

Issue date: Dec 1991

Interaction of height and mechanical loading of the spine in the development of low-back pain.

by Walsh K, Cruddas M, Coggon D

Affiliation: MRC Environmental Epidemiology Unit, University of Southampton, Southampton General Hospital, United Kingdom.

This article in PubMed: www.ncbi.nlm.nih.gov/pubmed/1838617 


\title{
Interaction of height and mechanical loading of the spine in the development of low-back pain
}

\author{
by Kevin Walsh MRCP, Marie Cruddas, PhD, David Coggon, MRCP1
}

\begin{abstract}
WALSH K, CRUDDAS M, COGGON D. Interaction of height and mechanical loading of the spine in the development of low-back pain. Scand J Work Environ Health 1991;17:420-4. The relation of lowback pain to height and physical activity was examined among 2667 British men and women aged 20-59 years and selected from the general population. Information about occupational activities, height, and lifetime history of low-back pain was obtained from a postal questionnaire. The lifetime prevalence of low-back pain was $58.3 \%$. After allowance for other occupational activities, the onset of low-back pain was strongly associated with heavy lifting at work (men: relative risk (RR) 2.0, $95 \%$ confidence interval (95\% CI) 1.4-2.8; women: RR 2.2, $95 \%$ CI 1.3-3.5). For the men there was also an association with digging (RR 1.6, $95 \%$ CI 1.1-2.3). Risk of low-back pain increased with height among the men but not among the women. The risks associated with heavy lifting and digging were greater for the short than for the tall men. Thus the data provide no justification for excluding tall men from heavy manual tasks, despite their greater susceptibility to back problems.
\end{abstract}

Key terms: digging, epidemiology, lifting, occupation.

Mechanical disorders of the lower back are thought to result from a combination of constitutional weakness and physical stress to the spine, although their exact pathogenesis is often uncertain. Among the stressful activities that have been linked with back disease are heavy lifting $(1-3)$ and twisting $(1,4,5)$. An apparent association with driving (6-9) could also be mediated by physical stresses, either from prolonged sitting or from vibration.

Various constitutional risk factors for back disorders have been investigated, but the most consistent evidence is for an association with height $(2,10-12)$. It is not known whether this relation occurs because tall people are more susceptible to the effects of physical stress or whether height influences risk independently of physical activity.

Study of the interaction between physical activity and height might add to our understanding of the pathological processes underlying back disease. Moreover, if tall people are particularly vulnerable to mechanical loading of the spine, this might be a consideration in the selection of personnel for heavy manual work. In this communication we report a survey in which we have related the onset of back symptoms to occupational activity and height and have given particular attention to their interaction.

\footnotetext{
${ }^{1}$ MRC Environmental Epidemiology Unit, University of Southampton, Southampton General Hospital, Southampton, United Kingdom.
}

Reprint requests to: Dr D Coggon, MRC Environmental Epidemiology Unit, University of Southampton, Southampton General Hospital, Southampton SO9 4XY, United Kingdom.

\section{Subjects and methods}

The study was carried out in six English towns (St Austell, Dorking, Wisbech, Ilkeston, Darwen, and Peterlee), one Scottish town (Arbroath), and a rural district of Wales (Radnor). In each area we selected a $5 \%$ random sample of men and women aged 2059 years from lists of all residents registered with local general practitioners. (In Britain almost everyone is registered with a general practitioner.)

These subjects were sent a postal questionnaire which asked for a lifetime occupational history, including the ages at which each job started and finished and whether an average workday involved any of the eight activities listed in table 1 . The subjects were also asked to give their height and to indicate whether they had ever had low-back pain that lasted more than a day in an area (illustrated in a diagram) between the twelfth ribs and the gluteal folds. Pain which only occurred during feverish illness, menstrual periods, or pregnancy was excluded. Those who reported low-back pain were asked at what age it first began, how long it had lasted altogether, and if they had had any associated disability. Nonresponders were sent a reminder after one month. Those who still failed to reply were sent a shorter questionnaire asking simply whether they had ever suffered from low-back pain, but not about occupation or height.

Associations of low-back pain with occupational activities and height were examined by Cox's proportional hazards model with allowance, where appropriate, for time-dependent covariates (13). As an illustration, the subset of subjects who reached 15 years of age without having had low-back pain provided an estimate of the risk of first developing low-back pain when aged 15 years in relation to occupational activities at the 15 th birthday. Similar information was avail- 
able for each year of age up to 60 . The method combined data from all ages to produce summary estimates of relative risk (RR) with $95 \%$ confidence intervals ( $95 \% \mathrm{CI}$ ). Allowance was made for the potential confounding effects of year of birth by stratification (in four 10-year intervals). Occupational risk factors were examined independently, and also simultaneously, in a model which assumed that, when factors were present in combination, their risks multiplied. Heights were analyzed in five levels defined by the quintiles of their distribution.

All but 10 of 146 local general practitioners agreed to take part in the study, and from their lists we selected 4502 subjects. Full questionnaires were completed by 1172 men and 1495 women - an overall response rate of $59.2 \%$. A further 525 subjects $(11.7 \%$ ) replied only to the shorter version. The lifetime prevalence of low-back pain was $58.3 \%$ for the subjects who answered the full questionnaire and $53.1 \%$ for those who only answered the shorter questionnaire. Subsequent analysis was restricted to the subjects who completed the full questionnaire, and it excluded 38 persons who first developed low-back pain before the age of 15 years and 121 persons who could not remember at what age their symptoms had started.

\section{Results}

Tables 1 and 2 show the risk of the men and women, respectively, first developing low-back pain in relation to the eight occupational activities studied. When the activities were examined independently, there were highly significant associations with lifting or moving heavy weights by hand among both the men (RR 2.2, $95 \%$ CI 1.6-3.1) and the women (RR 2.3, $95 \%$ CI 1.5-3.6). These risk estimates were only slightly diminished by allowance for other activities. The occupations which contributed the most to the association among the men were farmer ( 30 cases), engineering fitter (21 cases), and coal miner (18 cases). For the women the main contribution was from nurse ( 21 cases) and shelf filler (12 cases).

Among the men low-back pain was also associated with jobs that entailed digging or shoveling (RR 2.0, $95 \%$ CI 1.5-2.7, in independent analysis). After allowance for other activities this risk estimate was reduced, but it remained statistically significant. No association with digging was apparent for the women, but few women had been employed in this type of work.

None of the other occupational activities showed a clear relation to low-back pain. In particular, there was no association with car driving for either gender. An elevated risk among the male truck and tractor drivers disappeared after allowance for other activities. Of the postural variables studied, walking or standing for more than $2 \mathrm{~h}$ of the workday carried the highest risk of low-back pain. Again, however, the association was eliminated when other activities were taken into account.

No important differences were observed in the pattern of occupational associations when the analyses were restricted to low-back pain which made it impos-

Table 1. Risk of the men developing low-back pain according to occupational activity at preceding birthday. (RR = relative risk, $95 \% \mathrm{Cl}=95 \%$ confidence interval)

\begin{tabular}{|c|c|c|c|c|c|}
\hline \multirow[t]{2}{*}{ Activity } & \multirow{2}{*}{$\begin{array}{c}\text { Number of } \\
\text { cases } \\
\text { exposed }\end{array}$} & \multicolumn{2}{|c|}{$\begin{array}{c}\text { Each activity examined } \\
\text { independently }\end{array}$} & \multicolumn{2}{|c|}{$\begin{array}{l}\text { Activities examined } \\
\text { simultaneously }\end{array}$} \\
\hline & & RR & $95 \% \mathrm{Cl}$ & RR & $95 \% \mathrm{Cl}$ \\
\hline $\begin{array}{l}\text { Walking or standing for } \geq 2 \mathrm{~h} \\
\text { Sitting continuously for } \geq 2 \mathrm{~h} \\
\text { Sitting for } \geq 2 \mathrm{~h} \text { with or without breaks } \\
\text { Digging or shoveling } \\
\text { Driving a car or van for } \geq 4 \mathrm{~h} \\
\text { Driving a truck, tractor or digger } \\
\text { Using vibrating machinery } \\
\text { Lifting or moving weights of } \geq 25 \mathrm{~kg} \text { by hand }\end{array}$ & $\begin{array}{r}456 \\
101 \\
248 \\
136 \\
91 \\
120 \\
82 \\
352\end{array}$ & $\begin{array}{l}1.5 \\
0.7 \\
0.9 \\
2.0 \\
1.1 \\
1.6 \\
1.3 \\
2.2\end{array}$ & $\begin{array}{l}0.9-2.3 \\
0.5-1.1 \\
0.6-1.2 \\
1.5-2.7 \\
0.7-1.8 \\
1.1-2.4 \\
0.9-2.0 \\
1.6-3.1\end{array}$ & $\begin{array}{l}1.1 \\
0.6 \\
1.2 \\
1.6 \\
1.0 \\
1.1 \\
0.8 \\
2.0\end{array}$ & $\begin{array}{l}0.7-1.8 \\
0.4-1.1 \\
0.8-1.8 \\
1.1-2.3 \\
0.6-1.8 \\
0.7-1.7 \\
0.5-1.3 \\
1.4-2.8\end{array}$ \\
\hline
\end{tabular}

Table 2. Risk of the women developing low-back pain according to occupational activity at preceding birthday. (RR = relative risk, $95 \% \mathrm{Cl}=95 \%$ confidence interval)

\begin{tabular}{|c|c|c|c|c|c|}
\hline \multirow[t]{2}{*}{ Activity } & \multirow{2}{*}{$\begin{array}{c}\text { Number of } \\
\text { cases } \\
\text { exposed }\end{array}$} & \multicolumn{2}{|c|}{$\begin{array}{c}\text { Each activity examined } \\
\text { independently }\end{array}$} & \multicolumn{2}{|c|}{$\begin{array}{l}\text { Activities examined } \\
\text { simultaneously }\end{array}$} \\
\hline & & RR & $95 \% \mathrm{Cl}$ & RR & $95 \% \mathrm{Cl}$ \\
\hline Walking or standing for $\geq 2 \mathrm{~h}$ & 303 & 1.5 & $1.1-2.2$ & 1.0 & $0.6-1.6$ \\
\hline Sitting continuously for $\geq 2 \mathrm{~h}$ & 105 & 0.8 & $0.5-1.2$ & 1.3 & $0.8-2.2$ \\
\hline Sitting for $\geq 2 \mathrm{~h}$ with or without breaks & 217 & 0.6 & $0.4-0.8$ & 0.6 & $0.3-0.9$ \\
\hline Digging or shoveling & 10 & 1.1 & $0.3-3.8$ & 0.3 & $0.0-2.8$ \\
\hline Driving a car or van for $\geq 4 \mathrm{~h}$ & 17 & 1.2 & $0.3-5.5$ & 1.4 & $0.2-8.2$ \\
\hline Driving a truck, tractor or digger & 3 & 2.8 & $0.7-12.4$ & 4.5 & $0.3-65.0$ \\
\hline Using vibrating machinery & 6 & 2.3 & $0.6-9.7$ & 2.7 & $0.6-12.8$ \\
\hline Lifting or moving weights of $\geq 25 \mathrm{~kg}$ by hand & 82 & 2.3 & $1.5-3.6$ & 2.2 & $1.3-3.5$ \\
\hline
\end{tabular}


sible to put on socks, stockings, or tights or which lasted a total of more than 12 months.

The relation of low-back pain to stature is shown in table 3. The risk of symptoms among the men increased with height $(\mathrm{P}<0.0001)$ such that those taller than $183 \mathrm{~cm}$ were twice as likely to develop pain as those shorter than $171 \mathrm{~cm}$. In contrast, no trend with height was found for the women.

Tables 4 and 5 show the interactions of height with lifting and digging for the men. In a comparison with the unexposed subjects of the same height, the exposed subjects who were the shortest were observed to have the highest risks from lifting (RR 4.5) and digging (RR 3.3). For the men exposed to digging and lifting risk increased little with height.

Table 3. Risk of developing low-back pain according to height. ( $R R=$ relative risk, $95 \% \mathrm{CI}=95 \%$ confidence interval)

\begin{tabular}{llll}
\hline $\begin{array}{l}\text { Height } \\
(\mathrm{cm})\end{array}$ & $\begin{array}{c}\text { Number } \\
\text { of } \\
\text { cases }\end{array}$ & RR & $95 \% \mathrm{Cl}$ \\
\hline
\end{tabular}

\begin{tabular}{lrll}
\hline $\begin{array}{l}\text { Men }^{\mathrm{a}} \\
\leq 170\end{array}$ & 122 & 1 & \\
$171-174$ & 101 & 1.1 & $0.9-1.5$ \\
$175-178$ & 151 & 1.6 & $1.2-2.0$ \\
$179-183$ & 170 & 1.5 & $1.1-1.8$ \\
$\geq 184$ & 90 & 2.0 & $1.5-2.7$ \\
Women $^{\mathrm{b}}$ & & & \\
$\leq 157$ & & & \\
$158-160$ & 250 & 1 &. \\
$161-163$ & 96 & 0.9 & $0.7-1.2$ \\
$164-168$ & 115 & 0.9 & $0.8-1.2$ \\
$\geq 169$ & 175 & 1.1 & $0.9-1.4$ \\
\hline
\end{tabular}

a $\mathrm{P}$ for linear trend $<0.0001$.

b $\mathrm{P}$ for linear trend $>0.2$.

\section{Discussion}

This study adds to the evidence that heavy lifting and twisting cause or aggravate back disease, but it gives no support to the proposed etiologic role of driving. An association with height was found for the men, but not for the women. The association could not be explained by a greater susceptibility of the tall men to the effects of heavy lifting and digging at work.

In interpreting these observations it is important to make allowance for potential weaknesses in the study method. A particular concern is the accuracy with which the subjects recalled and dated exposure to risk factors and the onset of symptoms. We had no standard against which to validate the information that we elicited, but, when we sent duplicate questionnaires to a subsample of 225 men and women at an interval of 12 months, we found good agreement on whether the subjects had ever suffered from low-back pain (14). Moreover, of the 106 subjects who reported low-back pain on both questionnaires, $87 \%$ agreed to within five years on the age of onset, and $59 \%$ to within one year. To reduce the chance of bias, we did not ask the subjects directly about the work that they were doing when their symptoms began. Instead our questionnaire contained separate sections on occupation and symptom history with other questions in between. In the absence of systematic misreporting, the effect of errors in recall would usually be to obscure rather than to exaggerate associations.

Another possible source of bias was the incomplete response to the questionnaire. However, the similar prevalence of low-back pain for the subjects who completed the full questionnaire and the initial nonresponders who later replied to the shorter question-

Table 4. Risk of the men developing low-back pain according to height and whether job at preceding birthday entailed regular heavy lifting. (RR = relative risk, $95 \% \mathrm{Cl}=95 \%$ confidence interval)

\begin{tabular}{|c|c|c|c|c|c|c|}
\hline \multirow[b]{2}{*}{$\begin{array}{l}\text { Height } \\
(\mathrm{cm})\end{array}$} & \multicolumn{3}{|c|}{ Not exposed to heavy lifting } & \multicolumn{3}{|c|}{ Exposed to heavy lifting } \\
\hline & $\begin{array}{c}\text { Number } \\
\text { of } \\
\text { cases }\end{array}$ & RR & $95 \% \mathrm{Cl}$ & $\begin{array}{c}\text { Number } \\
\text { of } \\
\text { cases }\end{array}$ & $\mathrm{RR}$ & $95 \% \mathrm{Cl}$ \\
\hline $\begin{array}{l}\leq 170 \\
171-174 \\
175-178 \\
179-183 \\
\geq 184\end{array}$ & $\begin{array}{l}39 \\
41 \\
59 \\
57 \\
31\end{array}$ & $\begin{array}{l}1 \\
2.7 \\
2.3 \\
2.4 \\
5.4\end{array}$ & $\begin{array}{l}1.1-6.8 \\
1.0-5.5 \\
1.0-5.7 \\
2.2-13.5\end{array}$ & $\begin{array}{l}65 \\
54 \\
87 \\
96 \\
49\end{array}$ & $\begin{array}{l}4.5 \\
4.4 \\
5.7 \\
5.6 \\
5.2\end{array}$ & $\begin{array}{l}2.0-10.2 \\
1.9-10.0 \\
2.6-12.4 \\
2.6-12.1 \\
2.2-12.7\end{array}$ \\
\hline
\end{tabular}

Table 5. Risk of the men developing low-back pain according to height and whether job at preceding birthday entailed regular digging or shoveling. ( $\mathrm{RR}=$ relative risk, $95 \% \mathrm{Cl}=95 \%$ confidence interval)

\begin{tabular}{|c|c|c|c|c|c|c|}
\hline \multirow[b]{2}{*}{$\begin{array}{l}\text { Height } \\
(\mathrm{cm})\end{array}$} & \multicolumn{3}{|c|}{ Not exposed to digging or shoveling } & \multicolumn{3}{|c|}{ Exposed to digging or shoveling } \\
\hline & $\begin{array}{c}\text { Number } \\
\text { of } \\
\text { cases }\end{array}$ & RR & $95 \% \mathrm{Cl}$ & $\begin{array}{c}\text { Number } \\
\text { of } \\
\text { cases }\end{array}$ & RR & $95 \% \mathrm{Cl}$ \\
\hline $\begin{array}{l}\leq 170 \\
171-174 \\
175-178 \\
179-183 \\
\geq 184\end{array}$ & $\begin{array}{r}81 \\
70 \\
111 \\
121 \\
58\end{array}$ & $\begin{array}{l}1 \\
1.7 \\
1.9 \\
2.1 \\
2.8\end{array}$ & $\begin{array}{c}\cdot \\
0.9-3.3 \\
1.0-3.4 \\
1.2-3.7 \\
1.4-5.4\end{array}$ & $\begin{array}{l}24 \\
25 \\
34 \\
31 \\
22\end{array}$ & $\begin{array}{l}3.3 \\
3.3 \\
3.8 \\
3.3 \\
3.9\end{array}$ & $\begin{array}{l}1.6-6.9 \\
1.6-6.9 \\
1.9-7.4 \\
1.6-6.5 \\
1.7-8.9\end{array}$ \\
\hline
\end{tabular}


naire suggests that the responders were not atypical in their history of symptoms. The failure of a minority of general practitioners to participate in the study is unlikely to have had an important impact on the observed associations.

Of all the occupational activities studied, heavy lifting showed the strongest relation to low-back pain. The association was present for both genders and was little affected by allowance for other aspects of work. This finding is consistent with that of most other studies which have examined risks from manual handling $(1-3,15)$, although a few have failed to demonstrate associations $(16-18)$. The discrepancy may arise from the use of different definitions of lifting. Perhaps only the handling of heavier weights is relevant.

Digging entails both twisting and lifting and was therefore expected to carry an increased risk of lowback pain. This expectation was confirmed. The absence of an association with digging among the women is of little consequence given the small number of women exposed to the activity and the resultant lack of statistical power to detect an effect.

Information about driving came mainly from the men. In contrast to manual handling, driving a car or van at work was not related to low-back pain. Nor was there an association with truck and tractor driving once the impact of other activities had been taken into account. Our failure to demonstrate an effect of car driving is particularly noteworthy in view of the strict definition of exposure that we employed - at least $4 \mathrm{~h} / \mathrm{d}$. Our study was not large enough to exclude a small increase in risk, particularly as errors in recall may have had a masking effect. However, it casts doubt on the association with low-back pain found in an earlier, smaller study (19). At the same time, it is still possible that driving has an important influence on subcategories of back disease, in particular prolapsed intervertebral disc $(8,9,18,20)$.

Risk of low-back pain was clearly increased among the tall men, but it was not related to height among the women. This difference between the genders is unlikely to be explained by bias in the study method. In particular, there is no reason why men should report heights more accurately than women. Most other studies that have examined the relation of back disorders to height have concentrated on men. Positive associations have been reported with low-back pain among male airport luggage handlers (21), with lowback pain and radiographic disc degeneration among coal miners (2), with disc prolapse among American military personnel (22), and with low-back pain in samples of Danish men drawn from the general population $(10,11)$. Case-referent investigations in the United States (18) and Finland (12) have shown an increased risk of lumbar disc prolapse for taller women, as well as for taller men, but other studies based on less specific disease outcomes among women do not support this observation. In particular, low-back pain was not related to height in surveys of Swedish (23) and Dan- ish (11) women from the general population. The last investigation is of special interest since it did show an association between height and lifetime prevalence of low-back pain among men. Not all studies of men have indicated an effect of height $(5,20)$, but the balance of evidence strongly favors a relation. Given the findings of other population surveys, we suggest that our failure to demonstrate an increased risk of lowback pain for taller women may have arisen from a real difference between the genders.

A difference between men and women in the relation of low-back pain to height might be explained if the influence of height were determined by increased susceptibility to the effects of mechanical stress. Under such circumstances men would be expected to show a stronger association because they tend to expose their spines to greater loads. However, our analysis of the interaction between height and manual handling did not support this theory. The risks associated with heavy lifting and digging were higher for the short men than for the tall ones. Thus, if mechanical loading has a role in the excess of low-back pain among tall men, the relationship must be complex. Perhaps, for example, dose-response relations vary with height so that tall men are more vulnerable than short men when lifting moderate weights, but there is no difference in the risk for heavier lifting.

Whatever the explanation, our findings provide no justification for excluding tall men from heavy manual tasks.

\section{Acknowledgments}

We thank the general practitioners who allowed us to approach their patients.

Dr Walsh was supported by a fellowship provided by ESSO UK plc.

\section{References}

1. Frymoyer JW, Pope MH, Costanza MC, Rosen JC, Goggin JE, Wilder DG. Epidemiologic studies of low back pain. Spine 1980;5:419-23.

2. Lawrence JS. Rheumatism in coal miners: III. occupational factors. Br J Ind Med 1955;12:249-61.

3. Svensson HO, Andersson GBJ. Low-back pain in 40 to 47 year old men: work history and work environment factors. Spine 1983;8:272-6.

4. Buckle PW, Stubbs DA, Baty D. Musculo-skeletal disorders (and discomfort) and associated work factors. In: Corlett N, Wilson J, Manenica I, ed. The ergonomics of working postures. London: Taylor and Francis, 1986.

5. Saraste H, Hultmann G. Life conditions of persons with and without low-back pain. Scand J Rehabil Med 1987; 19:109-13.

6. Frymoyer JW, Pope MH, Clements JH, Wilder DG, McPherson B, Ashikaga T. Risk factors in low back pain: an epidemiological survey. J Bone Jt Surg 1983; 65A:213-8.

7. Kelsey JL. An epidemiological study of the relationship between occupations and acute herniated lumbar intervertebral discs. Int J Epidemiol 1975;4:197-205.

8. Kelsey JL, Hardy RJ. Driving of motor vehicles as a 
risk factor for acute herniated lumbar intervertebral discs. Am J Epidemiol 1975;102:63-73.

9. Heliövaara M. Occupation and risk of herniated lumbar intervertebral disc or sciatica leading to hospitalization. J Chronic Dis 1987;40:259-64.

10. Gyntelberg F. One year incidence of low back pain among male residents of Copenhagen aged 40-59. Dan Med Bull 1974;21:30-6.

11. Biering-Sorensen F. Physical measurements as risk indicators for low-back trouble over a one-year period. Spine 1984;9:106-19.

12. Heliövaara M. Body height, obesity and risk of herniated lumbar intervertebral disc. Spine 1987;12:469-72.

13. Peto R, Pike MC, Armitage $P$, et al. Design and analysis of randomized clinical trials requiring prolonged observation of each patient: II. analysis and examples. $\mathrm{Br}$ J Cancer 1977;35:1-39.

14. Walsh K, Coggon D. Reproducibility of histories of low back pain obtained by self-administered questionnaire. Spine (in press).

15. Kelsey JL, Githens PB, White AA, et al. An epidemiologic study of lifting and twisting on the job and risk for acute prolapsed lumbar intervertebral disc. J Orthop Res 1984;2:61-6.

16. Ảstrand N-E. Medical, psychological and social factors associated with back abnormalities and self-reported back pain: a cross-sectional study of male employees in a Swedish pulp and paper industry. Br J Ind Med 1987;
$44: 327-36$.

17. Damkot DK, Pope MH, Lord J, Frymoyer JW. The relationship between work history, work environment and low back pain in men. Spine 1984;9:395-9.

18. Kelsey JL. An epidemiological study of acute herniated lumbar intervertebral discs. Rheumatol Rehabil 1975;14: 144-59.

19. Walsh K, Varnes N, Osmond C, Styles R, Coggon D. Occupational causes of low-back pain. Scand $\mathbf{J}$ Work Environ Health 1989;15:54-9.

20. Kelsey JL, Githens PB, O'Connor T, et al. Acute prolapsed lumbar intervertebral disc: an epidemiologic study with special reference to driving automobiles and cigarette smoking. Spine 1984;9:608-13.

21. Undeutsch K, Gartner KH, Luopajärvi T, et al. Back complaints and findings in transport workers performing physically heavy work. Scand J Work Environ Health 1982;8(suppl 1):92-6.

22. Hrubec Z, Nashold BS. Epidemiology of lumbar disc lesions in the military in World War II. Am J Epidemiol 1975;102:366-76.

23. Hirsch C, Jonsson B, Lewin T. Low-back symptoms in a Swedish female population. Clin Orthop 1969;63: $171-6$.

Received for publication:18 March 1991 